Boise State University

ScholarWorks

Civil Engineering Faculty Publications and

Presentations

6-2019

Predicting Power-Transformer Bushings' Seismic Vulnerability:

Mounting Stiffness and Coupling

Jon Bender

Boise State University

Arvin Farid

Boise State University 


\title{
Predicting Power-Transformer Bushings’ Seismic Vulnerability: Mounting Stiffness and Coupling
}

\author{
Jon Bender and Arvin Farid
}

\begin{abstract}
Affiliations
Jon Bender has a Masters Degree in Civil Engineering from Boise State University and is currently working as an EIT at WE Gundy \& Associates, Inc. in Boise, Idaho.
\end{abstract}

Arvin Farid is an associate professor in the Civil Engineering Department at Boise State University.

\begin{abstract}
Large power transformers are both expensive and vulnerable to seismic failure. Excessive amplification of earthquake loading to power transformer bushings beyond the bushings' rated strength can occur if the system's structural dynamics produce unpredictable and unfavorable resonance behavior. Determining the degree of vulnerability to large seismic amplifications is not straight-forward, and general design recommendations do not always resolve problems that can potentially arise. This paper considers a number of Case studies in an attempt to postulate a set of critical factors, which might facilitate better prediction of bushing amplification. Further, several additional Case studies are summarized in order to add to the evaluated dataset and provide more validity for drawing broader conclusions.
\end{abstract}

\section{Introduction}

As urban centers continue to grow, demands for electric-power production, transmission, and distribution are modernizing and expanding in kind. With this expansion, power outages become costlier, both economically and with regard to physical safety. For this reason, it is increasingly urgent to ensure the security of our power supply. In seismic zones, where significant earthquake risks exist, this security means that thoughtful design is necessary for all critical components of an electrical grid.

Power transformers are among the most expensive components of large electrical networks, both in terms of manufacturing and installation costs. During earthquakes, these pieces of equipment can be highly vulnerable structurally, in part, due to their structural complexity, inherently resulting in more potential failure points (Anagnos 1999). This complexity is also partly responsible for the difficulty of accurate seismic evaluation of these large (i.e., $2 \mathrm{MN} / 500,000 \mathrm{lb}$ or larger) steel tanks and their attached components. Among the most vulnerable components are the insulating bushings, typically mounted to the cover of the transformer tank (Figure 1). These bushings have failed / broken frequently during numerous seismic events (Ma and Xie, 2018). The consequence of a broken bushing is the complete failure and shut-down of the transformer, the replacement of which is not easy or quick. Such a shut-down can render the entire "down-stream” portion of the electrical grid inoperative, and depending on the situation, this could affect as many as hundreds of thousands of people.

The preferred method to accomplish the challenging task of verifying the seismic capability of power transformers is the finite-element method of analysis. With modern computers, complex and detailed modeling with accurate results is both feasible and widely accepted in the industry.

Through the careful use of this numerical tool, what was once treated as a solid "rigid" box can now be demonstrated (more accurately) to be a ductile assemblage of steel components encasing a massive body of fluid (insulating oil) and an even more massive electrical core-and-coil system. Further, the "appendages” protruding from this enormous vessel can be evaluated in consideration of the typically flexible behavior of their interaction with the massive tank (Figure 1). It is this dynamic behavior that may be the key to solving the problem of unexpected seismic failures of power transformers. 
This is an author-produced, peer-reviewed version of this article. The final, definitive version of this document can be found online at Journal of Performance of Constructed Facilities, published by the American Society of Civil Engineers (ASCE). Copyright restrictions may apply. doi: 10.1061/(ASCE)CF.1943-5509.0001286

It is well understood that altering the mounting height of a structure affects its dynamic behavior. Since earthquakes impose cyclic loading (vibration), the modal characteristics of a given structure have a dramatic impact on its response to a seismic event. ASCE / IBC (American Society of Civil Engineers / International Building Code) standards include extensive provisions to account for these kinds of dynamic interactions, through both direct dynamic analysis and more conservative static "equivalent" methods. In either case, both structure height and mounting height are given appropriate consideration (ASCE 2016).

A major challenge with transformer analysis and design is that their dynamic behavior falls outside the umbrella of typical buildings' behavior, for which, the above-mentioned civil engineering codes (ASCE / IBC) were developed. The development of standards for transformer analysis, therefore, typically falls under the pervue of the IEEE (institute for electrical and electronics engineers).

To date, a number of studies have been performed to help better understand the problem of large bushing amplifications, most of which predict dramatic amplifications for large power transformer (Ma et al. 2017a, 2017b; Villaverde et al. 2001). Many of these studies have shown that amplifications can exceed those prescribed by the relevant standard (IEEE 693 2005) by a significant margin. Additional numerical and experimental investigations have been done to evaluate the performance of bushings, both independently supported and mounted on transformers which highlight their vulnerability (Gilani et al. 1998, 1999a, \& 1999b; Reinhorn et al. 2011; Koliou et al. 2012). As a result of this work, in general, there have been two key conclusions drawn. The first conclusion has been to recommend looking for the possibility of dynamic coupling between the transformer tank and the bushings. That is to say that caution is warranted when the primary frequencies for the tank are the same (or nearly so) as the bushing. When this happens, both systems resonate together leading to higher load amplifications (i.e., they move together and produce a whipping effect that greatly amplifies the load to the bushings). This is perhaps best described by Filiatrault (2005). As will be clear from the data presented in this paper, dynamic coupling is indeed a significant concern.

The second conclusion has been to recommend maximizing the stiffness of the system. In 2013, Koliou showed that this can have a significant beneficial impact on the bushing performance. This recommendation is consistent with decades of work in the field of structural dynamics (Chopra 2000). It is also congruent with the standard for transformer-bushing testing recommended by IEEE where a rigid-mounted bushing-fixed to a small, rigid frameis shaken on an earthquake-simulating shaking table using an earthquake record at double the accelerations of the maximum-expected real-world event at the installation location. It is thus assumed that the rigid-mounted bushing test configuration is expected to deliver less (at most half, in this case) the loading to the bushing compared with any transformer-mounted configuration. Hence, one would assume that the stiffest possible transformer-system configuration would be ideal, as it would minimize the increase in flexibility between the bushing-test configuration and the transformer-mounted configuration (IEEE 2005).

The practical problem with maximizing bushing mounting stiffness for large, massive transformers, however, is that creating sufficient stiffness can be cost-prohibitive and often geometrically prohibitive, especially since the bushingmounting locations are frequently limited by electrical clearance requirements.

The common practice has, therefore, been to design the system based first on electrical requirements and then to add more stiffness to the extent that is practical, and with consideration paid to cost. Figure 2 illustrates one example of steel-frame elements added to increase the stiffness of the bushing mounting for a large transformer.

\section{Methodology}

A total of five case studies are considered for this paper. In each case, a particular, real-world, high-voltage transformer with mounted bushings is evaluated for the amplification effects from the specific bushing-mounting configuration(s). Then, the mounting configuration(s) for each case is varied to determine the effects of increased and decreased mounting stiffness. The first three case studies are reviewed and summarized from prior work (Bender 2018). Based on those results, two new case studies are prepared for this paper with the goal of potentially validating, refining, and/or refuting the results from the first three cases, with particular attention paid to the most complex circumstances. Thus, the primary purpose of this paper is to add clarity and validity to the results of previous studies, and to begin parsing out the relevant design parameters which could potentially aid in future loss prevention.

A summary of the critical parameters of all five case studies is presented in Table I. 
This is an author-produced, peer-reviewed version of this article. The final, definitive version of this document can be found online at Journal of Performance of Constructed Facilities, published by the American Society of Civil Engineers (ASCE). Copyright restrictions may apply. doi: 10.1061/(ASCE)CF.1943-5509.0001286

\section{Initial Case Studies (1 Through 3)}

Initially, four bushing-mounting configurations with various bushing-mounting stiffness values, were analyzed in an effort to flesh out the potentially problematic assumptions associated with simplified analysis methodologies (Bender 2018). The following is a summary of the methodology and results from these studies. All modeling was performed using established finite-element techniques with the software SAP2000 (Computers and Structures 2010).

The bushings analyzed in these three cases were: a) a $230 \mathrm{kV}$ composite bushing, mounted vertically on a 2,000kN transformer (450,000lb, Figure 3, Case 1); b) a $138 \mathrm{kV}$ porcelain bushing, mounted vertically on a $1,375 \mathrm{kN}$ transformer (310,000lb, Figure 5, Case 2); c) a 550kV composite bushing, mounted vertically on a 4,230kN transformer (950,000lb, Figure 6, Case 3); and d) an $800 \mathrm{kV}$ composite direct-current (DC) bushing, mounted horizontally on the same 4,230kN $(950,000 \mathrm{lb})$ transformer (Figure 6).

A three-step process was then implemented for each of the above-mentioned four Cases.

Step 1) Isolated bushings were first modeled (example for the $138 \mathrm{kV}$ bushing shown in Figure 4), and "tuned" to match the real-world bushing's dynamic behavior. The bushing models were restrained against tri-axial translation at the flange bolt locations, and seismic loads were imposed in order to develop the demands resulting from a simulated seismic event in the absence of any structure amplification. This mimics the conditions currently used to test highvoltage bushings on a shaking-table.

Step 2) Then the calibrated bushing model was "mounted" on the transformer model. The system was subjected to the same applied seismic loads and the resulting "mounted" bushing demands were compared with those developed in the isolated-bushing condition from step 1.

Step 3) Finally, the bushing-mounting condition stiffness was varied to determine the impact of such variances on the demand amplification to the bushing. An example of such a stiffness modification is illustrated in Figure 7.

The above three-step process was performed for all three case studies, using an applied loading according to the IEEE 693-2005 high seismic-performance level (1.0g peak ground acceleration) dynamic time history that closely follows the $2 \%$ damped required response spectrum (Figure 8).

Figure 1: Ground-acceleration spectra in $\mathrm{X}, \mathrm{Y}$, and $\mathrm{Z}$ directions as well as the $2 \%$ damped required response spectrum (RRS), according to IEEE693

For each bushing, the modal characteristics of both the bushing and the transformer tank were determined and recorded. Additionally, the bending-moment demands to the bushings, both independently fixed and in their variously stiffened mounted configurations, were recorded and compared. The results (shown in Table II and Figure 17 in the Results Section) confirmed those described by Filiatrault (2005) that coupled systems (where bushing frequencies are very close to tank frequencies) induce highly amplified bushing loads. However, it showed no consistent pattern regarding the effect of increased mounting configuration stiffness on bushing load amplification, contrary to results developed by Koliou (2013). Rather, the results seemed to indicate that the case-specific relationship between the frequency of the bushing mounting assembly and the frequency of the transformer tank has an impact on whether increasing or decreasing the mounting stiffness would benefit the bushings.

\section{Case Studies 4 and 5, Each Modeld in only Two Critical Configurations Based on Results of Case Studies 1-3}

In order to further elucidate the generality of the results described above, the authors prepared two additional case studies using the same bushing size (kV ratings) as those in Section 2.1 displaying the least intuitive response to mounting stiffness. These additional case studies followed the same procedures outlined in Section 2.1, with the addition of a second time history series, the input and single-degree-of freedom directional response plots for which are shown in Figures 9 and 10, respectively.

The first (Case 4) was a $1,900 \mathrm{kN}(427,000 \mathrm{lb}), 230 \mathrm{kV}$ transformer with porcelain bushings; and the second (Case 5) was a $1,650 \mathrm{kN}$ (371,000lb), $550 \mathrm{kV}$ transformer with composite bushings. Figures 11 and 12 show the two models developed for the $230 \mathrm{kV}$ transformer model and the associated isolated bushing model. Figures 13 and 14 illustrate the $550 \mathrm{kV}$ transformer and its HV bushing, respectively. 
This is an author-produced, peer-reviewed version of this article. The final, definitive version of this document can be found online at Journal of Performance of Constructed Facilities, published by the American Society of Civil Engineers (ASCE). Copyright restrictions may apply. doi: 10.1061/(ASCE)CF.1943-5509.0001286

As with the reviewed case studies 1-3, the mounting stiffness was varied for each transformer model. Figures 15 and 16 describe the mounting stiffness modifications evaluated for these case studies. Following the simulation of applied dynamic seismic loads to each model and each stiffness configuration, the same dataset of isolated- and transformermounted bushing loads was collected for comparison between all five case studies, in hopes of identifying patterns.

\section{Results}

For the two new case studies (4 and 5) developed as described above, and reviewed case studies 1-3 summarized above, the tank and bushing primary frequencies, the bushing loads, bushing amplifications, and the corresponding stiffness configurations are summarized in Table II. Figure 17 illustrates these same datasets.

\section{Discussion}

The results of this study can be interpreted in several ways some of which are summarized as follows.

1) The relationship between the primary frequencies of the bushing and tank correlates roughly to the degree of bushing amplification.

2) This relationship—between primary frequencies of the bushing and those of the transformer tank—affects whether increasing or decreasing the mounting stiffness would result in reduced bushing demands.

3) Amplification to bushings by transformers is often greater than the amplification factor of two (2x) prescribed by the commonly practiced standard (IEEE693-2005). Each of these indications are discussed in the following sections.

\section{Bushing and Tank Frequency Interdependence}

When the primary frequencies of the transformer tank and bushing are close to one another, larger amplifications appear more likely, and the bushing amplification seems to be much more sensitive to adjustments in the mounting stiffness. In order to accurately determine the tank frequencies, particular care should be taken so that the analysis of the system is performed in a manner consistent with the actual characteristics of the tank (i.e., system and component centers of gravity as well as restraining conditions are accounted for as accurately as possible).

Figure 17 illustrates how the difference between the frequencies of the tank and bushing affects the bushing amplification in these six case studies. From the data (e.g., Case Studies $1 \& 3$ ), it seems that this relationship is critical when considering the potential for seismic bushing failure in large power transformers. One of the two $800 \mathrm{kV}$ bushings is included in Figure 17 to illustrate how the interaction effects between the tank and bushing are directly related to the stiffness of the load transfer path to the foundation. Although this large $800 \mathrm{kV}$ bushing has dynamics similar to the second 550kV bushing (Case Study 5), its amplification effects are overcome by the high stiffness that results from the low mounting location/configuration and turret bracing directly to the foundation.

\section{Mounting Stiffness and Dynamic Coupling}

Figures 17, 18, and 19 illustrate how changes in the bushing-mounting stiffness affected the amplification to the bushings in each case study. Depending on the dynamic relation between the bushings and the tank, a more flexible mounting configuration could be either beneficial or problematic. If, for example, the bushing has very low fundamental frequencies, bringing the mounting system frequency (including the bushing, turrets, and any bracing) down through stiffening might decouple it from the tank and prevent resonance and excessive amplification. This appears to occur with both $550 \mathrm{kV}$ bushings studied. Figure 19 illustrates this effect with both $550 \mathrm{kV}$ bushings.

For the more common circumstance-wherein bushing frequencies are substantially higher than those of the transformer tank - it is generally assumed that a much stiffer mounting configuration should generally be preferable, and the $138 \mathrm{kV}$ Case 2 and the $230 \mathrm{kV}$ Case 5 bear this out. However, the data suggest that particular caution should be taken when bushing frequencies are higher than the tank frequencies by a margin of roughly $20 \%$ or less, as occurs with the Case $1230 \mathrm{kV}$ bushing. Figure 18 illustrates this point. 
This is an author-produced, peer-reviewed version of this article. The final, definitive version of this document can be found online at Journal of Performance of Constructed Facilities, published by the American Society of Civil Engineers (ASCE). Copyright restrictions may apply. doi: 10.1061/(ASCE)CF.1943-5509.0001286

\section{Excessive Amplification, Prediction and Mitigation}

The large bushing amplifications that resulted from the above-mentioned cases and configurations considered in this study 166 is the cause of primary concern with regard to the current common/standard practice.

The tank/bushing frequency interdependence and mounting stiffness/dynamic coupling effects described above can amplify one another when the tank and bushing frequencies are very close together, which occurs in the first $230 \mathrm{kV}$ bushing (Case Study 1) and the first 550kV bushing (Case Study 3) considered in this paper. In these cases, the bushing demands were very sensitive to changes in the mounting stiffness.

When large amplifications are expected and/or unavoidable, calculating the likely maximum demands to the bushings - in consideration of the specific system dynamics - and comparing those demands to the capacity (i.e., design strength) of those bushing could be a means to increase assurance that such dynamic systems have sufficient capacity to prevent failure. In the event that the remainder of the transformer design can be shown to perform according to the expected seismic demands, selecting a particular bushing that has sufficient capacity (as determined by transformer dynamic analysis) could be a cost-effective alternative to a system-level mitigation measure (e.g. base isolation). The results of this paper suggest that careful dynamic analysis of any large power transformer installed in a location with substantial seismic hazards (i.e. peak ground acceleration greater than $0.25 \mathrm{~g}$ ) is recommended.

\section{Further Study}

It would be highly valuable to add additional data points to this investigation in hopes of refining the parameters associated with excessive transformer bushing amplification. The results of such an extensive parametric study could be further validated through empirical testing of in situ transformer units (e.g., snapback tests to confirm dynamic characteristics) and/or simplified bushing mounting configurations exposed to simulated seismic events (i.e. on a shaking table).

\section{Acknowledgements}

Many thanks to local Boise engineering firm, W.E. Gundy and Associates Inc., for providing the transformer and bushing specifications for use in the numerical study as well as guidance regarding the finite-element modeling. Thanks also to the Boise State University Department of Civil Engineering for its support of this work.

\section{References}

Anagnos, T. (1999). "Development of an Electrical Substation Equipment Performance Database for Evaluation of Equipment Fragilities” (PEER) Berkeley: Pacific Earth-quake Engineering Research Center, University of California.

ASCE (2016). "Minimum Design Loads and Associated Criteria for Buildings and Other Structures. American Society for Civil Engineers, Structural Engineering Institute. ASCE Standard 7-16.

Bender, J. \& Farid, A. (2018). "Dynamic Vulnerability of Transformer Bushings, Complex Structural Dynamics and Seismic Amplification" Elsevier Journal of Engineering Structures, vol 162 (May) pp. 1-10

Chopra, A. K. (2000). "Dynamics of Structures, Theory and Applications to Earthquake Engineering," Prentice Hall, New Jersey.

Computers and Structures, Inc. (2010). SAP2000 Advanced V.14.2.4, Berkeley, CA

Filiatrault, A. \& Matt, M. H. (2005). “Seismic response of high-voltage transformer-bushing systems,” Earthquake Spectra, vol. 21 (November) pp.1009-1025

Gilani, A. S., Chavez, J. W., Fenves, G. L., and Whittaker, A. S. (1998). "Seismic Evaluation of 196 kV Porcelain Transformer Bushings.” PEER Report 1998/02, Pacific Earthquake Engineering Research Center, Univ. of California, Berkeley, CA.

Gilani, A. S., Whittaker, A. S., Fenves, G. L., and Fujisaki, E. (1999a). "Seismic Evaluation and Retrofit of 230-kV Porcelain Transformer Bushings.” PEER Report 1999/14, Pacific Earthquake Engineering Research Center, Univ. of California, Berkeley, CA.

Gilani, A. S., Whittaker, A. S., Fenves, G. L., and Fujisaki, E. (1999b). "Seismic evaluation of 550 kV porcelain transformer bushings.” PEER Report 1999/05, Pacific Earthquake Engineering Research Center, Univ. of California, Berkeley, CA. 
This is an author-produced, peer-reviewed version of this article. The final, definitive version of this document can be found online at Journal of Performance of Constructed Facilities, published by the American Society of Civil Engineers (ASCE). Copyright restrictions may apply. doi: 10.1061/(ASCE)CF.1943-5509.0001286

IEEE (2005). “IEEE Recommended Practice for Seismic Design of Substations,” IEEE Power Engineer Society, IEEE Standard 693-2005.

Koliou, M., Filiatrault, A. \& Reinhorn, A. (2013). "Seismic response of high-voltage transformer-bushing systems incorporating flexural stiffeners I \& II: numerical study,” Earthquake Spectra, vol. 29, pp. 1335-1367, (November)

Koliou, M., Filiatrauilt, A., Reinhorn, A., \& Oliveto, N. (2012). "Seismic Protetion of Transformerr Bushing Systems by Stiffening Techniques,” Technical Report MCEER-12-0002, June.

Ma, G. L. \& Xie, Q. (2018). "Seismic Analysis of a 500-kV Power Transformer of the Type Damaged in the 2008 Wenchuan Earthquake" Journal of the Performance of Constructed Factilities, vol 32 (April) pp. 1-10

Ma, G. L., Liao, D. F., He, C., and Xie, Q. (2017a). "Seismic performance of a 1100 kV transformer bushing.” High Voltage Engineering, 43(6), pp 2033-2041 (in Chinese).

Ma, G. L., Xie, Q., and Whittaker, A. S. (2017b). "Dynamic Interaction of High Voltage Transformer Bushings, Turrets and Tanks," Earthquake Spectra, in press.

Reinhorn, A. M., Oikonomou, K., Roh, H., Schiff, A., and Kempner, L., Jr. (2011). "Modeling and Seismic Performance Evaluation of High Voltage Transformers and Bushings.” Technical Report MCEER-11-0006, State Univ. of New York at Buffalo, Buffalo, NY.

Villaverde, R. Pardoen, G. C., \& Carnalla, S. (2001). "Ground Motion Ampoifcation at Flange Level of Bushings Mounted on Electrical Substaion Transformers," Earthquake Engineering and Structural Dynamics, 30(5), pp. 621-632 